\title{
HERMENÊUTICA EXISTENCIAL E PESQUISA EM PSICOLOGIA CLÍNICA: CAMINHOS POSSÍVEIS
}

\author{
HERMENEUTICS EXISTENTIAL AND RESEARCH IN CLINICAL \\ PSYCHOLOGY: POSSIBLE PATHWAYS
}

\author{
Danielle de Fátima da Cunha Cavalcanti de Siqueira Leite ${ }^{1}$ \\ Carmem Lúcia Brito Tavares Barreto ${ }^{2}$
}

\begin{abstract}
Resumo: O presente artigo apresenta uma possibilidade compreensiva para discutir os resultados de pesquisa em Psicologia Clínica. Ao reconhecer a existência humana enquanto radicalmente singular, aproxima-se da Hermenêutica Existencial de Heidegger e de Gadamer, atentando-se para ressonâncias desse pensamento para a prática e a pesquisa em Psicologia. Nessa direção, subdivide-se em dois momentos: apresentação de pressupostos hermenêuticos existenciais e a descrição do caminho revelado em um trabalho de tese. Por fim, pode-se afirmar que uma pesquisa "orientada" por tais pressupostos não possui um caminho previamente determinado por premissas teorético-explicativos. Assim como, toda compreensão, que dela possa se mostrar, constitui-se apenas numa possibilidade compreensiva, ou seja, num âmbito de visão pelo qual um fenômeno pode ser visto/compreendido.
\end{abstract}

Palavras-chave: Pesquisa qualitativa; Hermenêutica filosófica; Psicologia.

\begin{abstract}
The present article exposes a comprehensive possibility to discuss the results of research in Clinical Psychology. When recognizing human existence as radically singular, it approaches the Existential Hermeneutics of Heidegger and Gadamer, focusing on resonances of this thought for practice and research in Psychology. In this direction, it is subdivided in two moments: presentation of hermeneutic existential presuppositions and the description of the path revealed in a thesis. Ultimately, it can be said that a research "oriented" by such presuppositions does not have a method previously determined by theoreticalexplanatory premises. Just as all comprehension, which can be shown, is only a comprehensible possibility, that is, a horizon by which the phenomenon can be seen / understood.
\end{abstract}

Keywords: Qualitative research; Philosophical hermeneutics; Psychology

\section{Introdução: a pesquisa qualitativa em discussão}

\footnotetext{
${ }^{1}$ Doutora em Psicologia Clínica pelo programa de Pós-graduação da Universidade Católica de Pernambuco (UNICAP). Professora do Centro Universitário do Vale do Ipojuca (UNIFAVIP/DeVry), Caruaru, Pernambuco, Brasil. E-mail: daniellesiqueira_psico@hotmail.com

${ }^{2}$ Doutora em Psicologia Escolar e do Desenvolvimento Humano pelo Instituto de Psicologia da Universidade de São Paulo (USP). Professora do Programa de Pós-graduação e da graduação da Universidade Católica de Pernambuco (UNICAP), Recife, Pernambuco, Brasil. E-mail: carmemluciabarreto@hotmail.com
} 
O presente trabalho visa a apresentar o caminho desvelado em um trabalho de tese $^{3}$ que teve como objetivo problematizar a prática psicológica com famílias, ofertada por serviços-escola de cursos de Psicologias vinculados a Instituições de Ensino Superior de Pernambuco, adotando pressupostos da hermenêutica existencial ao modo de Heidegger e Gadamer. O interesse por tal temática revelou-se nas práticas das autoras, à medida que essas apontavam para a insuficiência do paradigma positivista-mecanicista para recolher as demandas que se apresentavam nas suas situações clínicas, inclusive, no que diz respeito à atenção a famílias.

Tal paradigma, ao revelar-se insuficiente para compreender a experiência humana, também se mostrava deficitário para “orientar” pesquisas no campo da Psicologia, voltadas para interrogar / compreender fenômenos existenciais, assim como a própria situação clínica em sua singularidade. Importa destacar que tais limitações já são apontadas por Dilthey (2011) desde o século XIX, ao afirmar que os fenômenos humanos, diferentemente dos da natureza, não podem ser explicados, mas tão somente compreendidos. E, nessa direção, prescindem de métodos diferentes dos empregados pelas ciências exatas. Nas palavras do autor (2011, p. 30):

\begin{abstract}
No âmbito da vida psíquica, os fatos não podem ser elevados à determinação exata, que é necessária para a comprovação de uma teoria por meio da comparação de suas consequências com tais fatos. [...] na área limítrofe entre a natureza e a vida psíquica, experimento e determinação quantitativa se comprovaram uteis de uma maneira semelhante àquela que se mostra como sendo o caso no conhecimento da natureza. Nas áreas centrais da psicologia, não é possível observar nada disso.
\end{abstract}

A busca por desvelar caminhos - métodos -, mais apropriados para "as ciências humanas", já vem guiando a trajetória de vários pesquisadores, resultando em um movimento heterogêneo, que tem em comum as críticas que tecem ao método científico (técnico-explicativo) para compreender fenômenos humanos e sociais. Tal movimento constitui-se no que comumente chamamos de "pesquisas qualitativas", perspectiva assumida pelo presente estudo.

Dentre as pesquisas qualitativas, o caminho assumido na tese supracitada aproxima-se dos estudos fenomenológicos de cunho hermenêutico à medida que compreende que a existência humana é radicalmente singular e indeterminada. E, nesse sentido, um estudo que se volta para compreender a experiência humana - ou mesmo situações existenciais -, demanda pelo desvelamento de caminhos que guardem a abertura

\footnotetext{
${ }^{3}$ SIQUEIRA LEITE, D. F. C. C. A prática Psicológica com Famílias: problematizando a prática no contexto de clínicas-escola. 2016. 168f. Tese (Doutorado em Psicologia Clínica), Universidade Católica de Pernambuco, Recife. Trabalho orientado pela professora doutora Carmem Lúcia Brito Tavares Barreto.
} 
que constitui a própria existência humana, encaminhando-se de modo a aguardar "pacientemente" que os fenômenos se revelem a partir do próprio vivido.

Importa reconhecer que existir é acontecer singularmente num mundo com os outros e, nessa direção, não pode ser previamente explicado, mas apenas compreendido a partir de uma aproximação com os horizontes que nele se "re-velam" e no recolhimento dos acontecimentos que se dão singularmente. A partir desse horizonte, a compreensão a partir de paradigmas meramente mensuradores e classificatórios revela-se insuficiente e, até mesmo, inapropriada.

A partir de tal compreensão, a proposta do presente trabalho não é indicar o modo de construção de generalizações ou, mesmo, a determinação de protocolos metodológicos que possam ser reaplicados em outras pesquisas. Sua proposta é apresentar um caminho possível, que foi apresentando-se no acontecer da pesquisa realizada para compor a tese citada. Caminho que foi mostrando-se à medida que as pesquisadoras - orientadora e orientanda - buscavam tecer compreensões possíveis acerca do fenômeno interrogado, não a partir da aplicação de premissas teorético-explicativas, mas pelo recolhimento daquilo que se mostrava a partir de aproximações com a própria situação interrogada: a prática psicológica com famílias no contexto de serviços-escola de IES de Pernambuco. Importa, pois, destacar que o caminho, que mais à frente será descrito, mostrou-se à medida que o caminhar das pesquisadoras foi orientando-se pelas perguntas: Como a prática psicológica com famílias se tem constituído no contexto de serviços-escola de Instituições de Ensino Superior de Pernambuco? A prática psicológica com família ainda está orientada por uma compreensão que privilegia uma noção de subjetividade intrapsíquica?

Ao retomar o objetivo do presente artigo, que busca refletir caminhos possíveis para a pesquisa qualitativa no campo da Psicologia Clínica, vale destacar que optamos por subdividi-lo em dois momentos reflexivos: o primeiro tem como objetivo apresentar alguns dos pressupostos hermenêuticos existenciais assumidos, e o outro volta-se para descrever o caminho "metodológico" que foi construindo-se durante a pesquisa desenvolvida no trabalho de tese. Com isso, esperamos contribuir para a consolidação de outros horizontes compreensivos para a pesquisa, no campo da Psicologia Clínica.

Antes, porém, cabe ressaltar que toda descrição ôntica, inclusive a pesquisa, está sempre dirigida por pressupostos ontológicos, sejam esses reconhecidos tematicamente ou não (FERRATER MORA, 2004), e, por isso, decidimos, no primeiro momento desse artigo apresentar quais pressupostos "orientaram" nosso caminhar. Todavia, importa 
ressaltar que compreender que toda descrição ôntica é "orientada" por pressupostos ontológicos não é a mesma coisa de dizer que toda pesquisa se sustenta, necessariamente, em um arcabouço teórico (premissas) prévio, que irá determinar quais são os procedimentos e protocolos que deverão ser seguidos e aplicados em uma determinada direção.

Faz-se necessário, então, explicitar a diferença entre premissas e pressupostos, visto que tal diferença pode apontar para direcionamentos diversos no que diz respeito ao acontecer de uma pesquisa. Premissas são juízos que racionalmente levam a deduções, “[...] são os antecedentes do raciocínio que dão lugar ao consequente ou conclusões" (FERRATER MORA, 2004, p. 2356). São proposições que levam a uma determinada conclusão, a partir de um encadeamento lógico-racional previamente determinado. E, nessa direção, é um pré-requisito para as pesquisas quantitativas e para algumas pesquisas qualitativas, a depender do horizonte compreensivo que a orienta. Enquanto os pressupostos (pré-supostos) nos remetem, apenas, a uma suposição, que "[...] não se trata de uma relação lógica, mas sim ontológica" (HEIDEGGER, 2009, p. 61 - grifo do autor). E, nessa direção, trata-se apenas de "indicações", horizontes que se apresentam na própria experiência, sem, todavia, ter pretensões a universalizações e/ou generalizações. Tais orientações, diferentemente das premissas, não determinam previamente aonde se irá chegar ao final de uma pesquisa ou, mesmo, de um jogo compreensivo.

\section{Pressupostos filosóficos: Heidegger e Gadamer}

Antes de iniciar tal discussão, é importante destacar que não pretendemos realizar uma ampla discussão do pensamento de Heidegger - de sua Analítica Existencial - ou mesmo da Hermenêutica Filosófica de Gadamer. Mas apenas realçar alguns dos pressupostos presentes no pensamento desses pensadores que podem ressoar na pesquisa e na prática psicológica, levando-nos à procura de outros caminhos / horizontes, que se destinem ao recolhimento da experiência humana em sua singularidade, assim, como a possibilidade de se pensar intervenções atentas ao próprio acontecer da situação clínica.

\subsection{A Analítica Existencial de Heidegger}

Importa lembrar que os pressupostos hermenêuticos existenciais, assim como vislumbrados por Heidegger, remetem à dimensão ontológica, enquanto a prática clínica 
e a pesquisa refere-se à dimensão ôntica. É, pois, impossível a simples transposição e aplicação de um horizonte sobre o outro. Todavia, tal diálogo torna-se possível e até mesmo necessário, à medida que o ôntico e o ontológico são duas faces / dimensões - que se tangenciam, sem se misturar - de um mesmo plano: a existência. E, nesse sentido, são frutíferas as ressonâncias que tais pressupostos podem apontar para a pesquisa e a prática no campo da Psicologia.

Tais ressonâncias podem apontar outros caminhos para a pesquisa e a prática psicológica mais afinados com a dimensão de mistério ${ }^{4}$, própria do existir humano. Tal direcionamento pode, também, romper com os caminhos técnicos "dis-postos" por premissas teorético-explicativas, que se mostram insuficientes para compreender as experiências que se revelam na prática psicológica. Assim, podem apontar para procedimentos metodológicos implicados no desenvolvimento de pesquisas que objetivam compreender tais experiências em sua singularidade e privilegiam dimensões existenciais da condição humana.

Heidegger (2008), em sua Analítica Existencial, revela a existência de um ente que, em sua condição de poder ser, tem a possibilidade de interrogar-se sobre o sentido do ser, uma vez que seu ser se encontra sempre em jogo em sua existência. Ao ser deste ente, que nós mesmos somos, ele nomeia de Dasein (ser-aí; ser-o-aí). Enuncia, assim, que todas as representações encapsuladas e objetificantes assumidas ao longo da nossa história - tais como, sujeito, self, ego, pessoa, consciência - para referir-se ao ser-dohomem deveriam desaparecer em favor de uma compreensão completamente diferente (HEIDEGGER, 2009). Haja vista que, tais compreensões não dão conta de compreender a existência humana em sua dimensão ontológica, originária. A esse respeito, Ferrater Mora (2005, p. 1305) observa que:

[...] a natureza própria do Dasein consiste em sua existência e ele não é apreendido mediante categorias, mas por meio dos "existenciais". Isso distingue a analítica do Dasein de toda psicologia ou antropologia, pois, o Dasein não é um ente como os demais; propriamente não é um ente, mas um existente, isto é, uma realidade em cujo ser está seu ser.

Assumir a compreensão do ser-do-homem enquanto Dasein direciona, pois, para o reconhecimento de sua dimensão ontológica enquanto abertura ao ser, poder-ser, pura possibilidade. Importa lembrar que possibilidade, aqui, não se refere a algo a ser

\footnotetext{
${ }^{4}$ A compreensão de mistério, aqui, assumida não remete a algo místico ou secreto, mas à própria dimensão ontológica do ser-do-homem enquanto abertura ao ser e indeterminação. Pois, como enuncia Heidegger (2011, p. 202), o "que não se fala não é somente o que não se deixa verbalizar, mas o não dito, o que ainda não se mostrou, o que ainda não chegou a aparecer. $\mathrm{O}$ que, portanto, deve manter-se impronunciado resguarda-se no não dito, abriga-se no velado como o que não se deixa mostrar, é mistério".
} 
realizado, mas diz da própria condição de indeterminação que constitui ontologicamente a existência. Vale, ainda, ressaltar que compreender o ser-do-homem enquanto possibilidade não é a mesma coisa de dizer que ele tem possibilidades, visto que não há nada, ontologicamente, que determine o ser-do-homem a ser isto ou aquilo.

\begin{abstract}
O ser-aí não é um ente que possua algum acesso cognitivo ao seu ser ou que tenha o seu ser desde o princípio como algo já constituído. O ser do ser-aí não é algo simplesmente subsistente de antemão, do qual ele se extravia por uma circunstância qualquer e ao qual ele precisa retornar por intermédio de um movimento reflexivo posterior. Ao contrário, o ser-aí é poder-ser e se mantém como poder-ser apesar de todas as configurações possíveis de si mesmo em que venha a efetivamente se apresentar. À medida que retém incessantemente o seu caráter de poder-ser, o ser-aí vem ao mesmo tempo à tona como existente (CASANOVA, 2006, p. 14).
\end{abstract}

O que possibilita dizer que o Dasein consiste em $e k$-sistere ${ }^{5}$, ser-para-fora, ser nomundo. Não há, aqui, nenhuma relação de dentro e fora como os paradigmas subjetivos ou objetivos propõem, mas existir já é ser fundamentalmente num mundo circundante, numa teia de sentido que o constitui e na qual se desvela sentido. "Encontrar-se no mundo" já é uma condição existencial e da qual o Dasein não pode abstrair-se. Nesta perspectiva, “[...] não há um sujeito em um mundo (realismo), nem um mundo em um sujeito (idealismo)", daí a importância do hífen (FERRATER MORA, 2005, p. 1305), pois existir é originariamente já ser-sempre-no-mundo, estar-no-mundo, encontrar-se-nomundo, condição originária.

Importa observar que a expressão Dasein é composta pelo verbo sein (ser) e pelo advérbio $D a$ (aí), e, neste sentido,

[...] o Dasein é ente a cuja essência pertence o ser; que existe (é) enquanto aí no aberto, em abertura para o ser. Essa é a condição ontológica do homem como Dasein, como ser-o-aí. Nesse sintagma, " $d a$ ” não deve ser tomado em acepção espacial, como se indicasse uma localização, um "aqui" contraposto a "lá" ou "acolá" (GIACOIA JUNIOR, 2013, p.63).

O ser-o-aí apresenta-se como ser-no-mundo-com-os-outros, abertura de sentido, o que implica dizer que só somos sempre no mundo junto aos demais entes que nos vêm ao encontro, nos tocam à medida que já estamos sempre em um modo de ser da abertura (compreensão e disposição afetiva). Enquanto ser-no-mundo, o homem encontra-se sempre bem ou maldisposto, visto que, como abertura, já encontra-se-no-mundo a partir de uma disposição afetiva e de uma pré-compreensão.

\footnotetext{
${ }^{5}$ Nessa perspectiva, não faz mais sentido falar em dentro ou fora (mundo interno X mundo externo), o que abre a possibilidade de "des-velar" um outro encaminhar para a Psicologia à medida que revela a impossibilidade de se compreender o paciente isolado de um mundo, no qual ele é, sem levar em consideração sua historiografia.
} 
Nessa perspectiva, Dasein não corresponde a uma "substância" ou "algosimplesmente-dado", visto que nossa existência se dá sempre numa estrutura de significância, num contexto de relações, "no-mundo" (SANTOS; SÁ, 2013). A este respeito, Hedeigger (2008, p. 175) chama atenção que:

O encontro com os outros não se dá numa apreensão prévia em que um sujeito, de início já simplesmente dado, se distingue dos demais sujeitos, nem numa visão primeira de si onde então se estabelece o referencial da diferença. Eles vêm ao encontro a partir do mundo em que a presença se mantém, de modo essencial, empenhada em ocupações guiadas por uma circunvisão ( grifo do autor).

Assim compreendido, ser e mundo não correspondem a duas substâncias isoladas e encerradas em si-mesmas, que só num segundo momento estabelecem uma relação entre elas, como nosso modo de pensar cotidiano nos permite acreditar. Ser e mundo são cooriginários, o que implica dizer que, quando nasce um ser-humano, inaugura-se um mundo, mundo que é sempre compartilhado com os outros. Nesse rumo, é possível compreender que só existe ser no mundo, assim como não há mundo sem ser. Mundo aqui compreendido como abertura na qual horizontes se "mostram", enquanto trama de sentido.

Pensar o ser-do-homem, enquanto Dasein implica, pois, assumi-lo como ser-nomundo, ser-em; e não como algo que se dá "dentro de...". Pois estar "dentro de..." remete a uma relação “[...] de ser de dois entes extensos 'dentro' do espaço, no tocante a seu lugar neste espaço" (HEIDEGGER, 2008, p.99). Ser-em remete ao sentido de morar, habitar, deter-se, enquanto condição originária. Nas palavras do filósofo:

[...] O ser-em não pode indicar que uma coisa simplesmente dada está, espacialmente, "dentro de outra" porque, em sua origem, o "em" não significa de forma alguma uma relação espacial desta espécie; "em" deriva-se de innan, morar, habitar, deter-se; "an" significa: estou acostumado a, habituado a, familiarizado com, cultivo alguma coisa; possui o significado de colo, no sentido de habitar e diligo. O ente, ao qual pertence o ser-em, neste sentido, é o ente que sempre eu mesmo sou. A expressão "sou" conecta-se a "junto", "eu sou" diz, por vez: eu moro, detenho-me junto... ao mundo, com alguma coisa que, deste ou daquele modo, me é familiar. Como infinitivo de "eu sou", isto é, como existencial, ser significa morar junto a, ser familiar com (HEIDEGGER, 2008, p. 100 - grifos do autor).

Importa lembrar que "ser-junto" não remete a um conjunto de coisas que ocorrem ao mesmo tempo; não significa "justaposição" entre dois entes simplesmente dados, haja vista que o ser-do-homem em sua essencialidade é possibilidade, poder-ser, abertura de sentido, é não uma substância ou coisa. E mundo é uma condição ontológica desse ser que nós mesmos somos, "é abertura de sentido, contexto de significação, linguagem" (SÁ; MATTAR; RODRIGUES, 2006, p.114). Destarte, podemos compreender que 
apenas o Dasein possui mundo, os demais entes estão no mundo à disposição - à mão -, revelando sentido ao se apresentarem a esse "aí" que nós mesmos somos, enquanto clareira do ser.

Ao compreender o ser-do-homem como ser-no-mundo, abre-se a possibilidade de recolher sua dimensão originária de ser-com e co-presença. Pois, como destaca Heidegger (2008, p. 174, grifo do autor),

[...] O mundo da presença libera, portanto, entes que não apenas se distinguem dos instrumentos e das coisas, mas, que, de acordo com seu modo de ser $d a$ presença, são e estão "no" mundo em que vêm ao encontro segundo o modo de ser-no-mundo. Não são algo simplesmente dado e nem algo à mão. São como a própria presença liberadora - são também co-presenças.

Ao destacar a dimensão originária do ser-com, Heidegger (2008) nos aponta para a impossibilidade de isolamento ou fechamento total do ser-do-homem, pois mesmo diante da solidão - ou seja, no modo do afastamento dos demais entes que são iguais a nós mesmos - somos sempre e originariamente "co-presença". A esse respeito, Sá, Mattar e Rodrigues (2006) destacam que a ausência do outro não remete a um vazio existencial, mas a um modo de ser da presença. Pois apenas aquele ser que é, em sua dimensão mais originária ser-com - "co-presença" -, pode experienciar-se no fenômeno da solidão. Apenas “[...] quem reconhece seus semelhantes, quem os sente próximos ou distantes" pode estar-sozinho (SÁ; MATTAR; RODRIGUES, 2006, p.118). Nesse sentido, estarsozinho não remete apenas à ausência ou à presença física do outro, mas um modo de serno-mundo.

Como bem enuncia Heidegger (2008, p. 174), “[...] os 'outros’ não significam todo o resto dos demais além de mim, do qual o eu se isolaria”, mas são aqueles entes os quais, na maior parte das vezes, não consigo me diferenciar, pois os outros “[...] são aqueles entre os quais também se está" (p. 174). Estar-com não se reduz a um ser simplesmente dado em conjunto dentro de um mundo, mas a uma determinação do sero-aí; e, também, revela "a igualdade do ser enquanto ser-no-mundo que se ocupa dentro de uma circunvisão" (HEIDEGGER, 2008, p.174). Podemos, pois, compreender que "à base desse ser-no-mundo determinado pelo com o mundo é sempre o mundo compartilhado com os outros. O mundo da presença é mundo compartilhado. O ser-em é ser-com os outros" (HEIDEGGER, 2008, p.175, grifos do autor). 
Ao compreender o Dasein enquanto ser-no-mundo-com-os-outros - projeto, cujo ser está sempre em "jogo" -, Heidegger desoculta a Cura - o Cuidado (Sorge) ${ }^{6}$ como unidade existencial-ontológica desse ser. Nessa direção, o termo Cura não indica uma atitude isolada do eu consigo mesmo, haja vista que, ontologicamente, Cura já se caracteriza como uma atitude de anteceder-a-si-mesmo, que engloba o já ser-em e o serjunto-a (ser-com). A esse respeito, Heidegger (2008) nos leva a pensar que:

\begin{abstract}
A totalidade existencial de toda a estrutura ontológica da presença deve ser, pois, apreendida formalmente na seguinte estrutura: o ser da presença diz antecerder-a-si-mesma-no-já-ser-em-(no mundo)-como-ser-junto-a (os entes que vêm ao encontro dentro do mundo). Esse ser preenche o significado do termo cura, aqui utilizado do ponto de vista puramente ontológico-existencial. Fica excluída desse significado toda tendência ôntica como cuidado ou descuido.

Porque, em sua essência, o ser-no-mundo é cura, pode-se compreender, nas análises procedentes, o ser junto ao manual como ocupação e o ser como copresença dos outros nos encontros dentro do mundo como preocupação (HEIDEGGER, 2008, p. 259-260, grifos do autor).
\end{abstract}

Heidegger aponta, assim, para dois modos fundamentais de ser-no-mundo-juntoaos-demais-entes: O modo da "ocupação" (Bersorgen), modo de ser / estar-junto aos entes desprovidos de mundo, que nos vêm ao encontro, na maior parte das vezes, como um ser simplesmente dado; e a "preocupação" (Fürsorge), modo de ser / estar-junto aos entes que são dotados do modo de ser da presença (este ser que nós mesmos somos).

A esse respeito, Santos e Sá (2013, p. 2013) apontam que, apesar dessa distinção, “o modo cotidiano e mediano da 'preocupação' com os outros é a 'indiferença', isto é, a suposição de evidências, a naturalização dos sentidos e o nivelamento das diferenças, que também caracterizam a 'ocupação' com as coisas do mundo”. O que implica dizer que, no modo de ser da cotidianidade mediana, na maior parte do tempo, tendemos a compreender as coisas, a nós mesmos e aos outros como ser simplesmente-dado, dotado de um sentido previamente definido, como algo já dado, já conhecido.

Para além desse modo da indiferença, Heidegger reconhece dois modos de sercom-os-outros: a preocupação substituidora e a preocupação libertadora. O primeiro modo revela um certo domínio ou subordinação sobre o outro, de modo que "determinamos" quais são as "melhores" direções que ele deve assumir em seu existir. Nós antecipamo-nos em sua tarefa de cuidar-de-ser-si-mesmo de modo que o

\footnotetext{
${ }^{6}$ Nas notas explicativas encontradas na edição brasileira de "Ser e Tempo" (2008, p.565), chama-se atenção que para a tradução do termo alemão Sorge quando se remete a condição ontológica, seria melhor o uso do termo latino Cura. Enquanto o termo cuidado e seus derivados seriam assumidos para acentuar "as realizações concretas do exercício da presença", ou seja, quando nos remetemos à dimensão ôntica do existir. Por isso, passamos a assumir, agora, o termo Cura para nomear essa unidade-existencial ontológica do Dasein.
} 
encontramos como algo simplesmente dado. Já no modo da anteposição libertadora, antecipamo-nos de modo a estar-com-o-outro na direção de convocá-lo a assumir sua condição originária de poder-ser, cuidar-de-ser-si-mesmo-no-mundo-com-os-outros. A “anteposição libertadora" revela-se como um modo de estar-junto (num modo de sercom) que acompanha o outro na sua tarefa de cuidar de ser si-mesmo, sem assumir - por ele - seus direcionamentos. Condição também indicada como solicitude, a qual se revela num aguardar que acolhe e acompanha - coloca-se lado a lado - sem, todavia, direcionar aquele a quem se acompanha para um lado ou para o outro, como se dá no modo da substituição.

Importa observar que, na cotidianidade, esses dois modos extremos - da "substituição" ou da "anteposição" / "solicitude" libertadora - mostram-se em uma infinidade de modos intermediários ou mesmo híbridos. E nem um ou outro modo de ser deve ser assumido como modo de ser ideal ou ser perseguido a qualquer custo, mas ambos são modos de ser-no-mundo "co-originários". Importando lembrar que, enquanto existimos, estamos constantemente transitando entre diferentes modos de ser-no-mundocom-os-outros.

Nessa direção, Ferrater Mora lembra-nos que, enquanto preocupação - ser-nomundo-com-os-outros,

[...] O Dasein pode, certamente, "despreocupar-se"; é o que acontece na existência cotidiana em que predomina o "alguém" (o "se", nas formas do "se vê", "se diz" etc). O "alguém" é como uma degradação do Dasein. Mas não é degradação moral; nem sequer é degradação ontológica no sentido de ser "menos": é uma degradação existenciária que o constitui o Dasein e, portanto, não deve ser julgada negativamente. É verdade que a descrição do Dasein como "caído" (verfallen) - como perpetuamente "distraído" pelas "tagarelices", pelo "afã de novidades" etc. - parece conduzir a uma "crítica da existência cotidiana". Não obstante, a queda do Dasein é uma de suas faces ontológicas. Com efeito, para cada uma das formas básicas da estrutura do Dasein - a "disposição" ou o "encontra-se-em" (Benfindlichkeit), o "compreender" (Verstehen) e a fala (Rede) - há dois aspectos: o da autenticidade, na recuperação de si mesmo por si mesmo ou apropriação, e o da inautencidade, ou queda, ou esquecimento de si mesmo, na distração. Ambos são existenciarimente constitutivos (FERRATER MORA, 2005, p. 1305).

Enquanto poder-ser-no-mundo-com-os-outros, o Dasein pode "achar-se" ou "perder-se" impessoalidade (inautenticidade) são modos co-originários. Sendo esse último o modo no qual o ser-do-homem se encontra, na maior parte das vezes, na cotidianidade, à medida

\footnotetext{
7 "Achar-se" ou "perder-se" não devem ser, aqui, assumidos num sentido valorativo, mas enquanto modosde-ser co-originários. Enquanto ser-no-mundo-com-os-outros, o homem pode encontrar a si (aos outro e ao mundo) de modo autêntico ou inautêntico.
} 
que se encontrar imerso no mundo do "todo mundo, ninguém" (do a gente). Mundo no qual há predominância do "falatório", de um dizer que de tudo se fala como se já soubesse e a tudo, inclusive, a si mesmo se compreende enquanto algo simplesmente dado, não guardando nenhum "lugar" para o "ainda-não". Já, na autenticidade, mostra-se como possibilidade ao Dasein apropriar-se de sua condição mais originária enquanto poder-ser, abertura, indeterminação originária. $\mathrm{O}$ que implica reconhecer que, por mais possibilidades ônticas que se possa concretizar, jamais se finaliza / realiza-se, pois, sua condição é a da possibilidade e não a da realidade. Vale, então, compreender que:

[...] É verdade que o estar-no-mundo é sempre um estar-no-mundo é sempre um estar-caído (um ter-caído), pois, afinal de contas, estar-no-mundo é ter sido lançado ao mundo, e esse ser lançado é como uma queda. Não menos certo, porém, que o Dasein tem a possibilidade de "levantar-se" dessa "queda". Isso acontece mediante a angústia, na qual o Dasein compreende em sua niilidade ontológica. Esta não é resultado de um ser essencialmente criatura, mas de um não ser propriamente "nada" (FERRATER MORA, 2005, p. 1305).

A angústia singulariza o Dasein em seu ser-no-mundo, nas palavras de Heidegger (2008, p. 254 - grifo do autor) “[...] a angústia revela o ser para o poder ser mais próprio, ou seja, o ser-livre para a liberdade de escolher e acolher a si. A angústia arrasta a presença para o ser-livre para... (propensio in...), para a propriedade de seu ser enquanto possibilidade de ser [...]" si-mesmo-no-mundo-com-os-outros. "Ser-si-mesmo", aqui, não corresponde a nenhum "em-si" ou, mesmo, a realização de alguma substancialidade, essencialidade e/ou potencialidade, mas a possibilidade de o Dasein - em seu ser-nomundo - assumir-se enquanto nada, abertura de sentido, indeterminação, ser-para-morte. A angústia, a partir desse horizonte, antes de manifestar-se como um sintoma patológico, revela-se como uma disposição afetiva fundamental, que mantém aberta a possibilidade de destinarmo-nos para decisões mais próprias.

Por fim, importa lembrar que a autenticidade e a inautenticidade, a partir de tal horizonte compreensivo, não correspondem a estágios ou fases do desenvolvimento humano, mais são modos de ser pelos quais podemos nos encontrar-no-mundo-com-osoutros-e-nós-mesmos.

\subsection{A Hermenêutica Filosófica de Gadamer}

Passemos, agora, a nos aproximar de alguns dos pressupostos revelados na Hermenêutica Filosófica de Gadamer, discípulo de Martin Heidegger, cujo pensamento também se fez importante para o encaminhamento da tese citada, cujo percurso 
"metodológico" pretendemos refletir neste trabalho. Acerca da Hermenêutica Filosófica, Schwandt (2008) destaca que ela se constitui em uma das posturas epistemológicas contemporâneas viáveis às pesquisas qualitativas.

A partir do horizonte assumido por Gadamer, reconhecendo as ressonâncias de Heidegger em seu pensamento, faz-se necessário assumir a compreensão enquanto condição ontológica do ser-do-homem. Nessa perspectiva, a compreensão não se vincula a uma verdade constituída previamente enquanto adequação do real - veritas (CASANOVA, 2010). Mas o sentido de verdade aproxima-se da compreensão originária de alethéia, enquanto aquilo que se "re-vela". Só podendo ser pensada "em profunda intimidade com o ser, concebido como phýsis" - vigor do real que possibilita que tudo brote, conserve e desapareça (MICHELAZZO, 1999, p. 30). Nesse sentido, verdade corresponde a "des-velamento" e a compreensão:

[...] não é um ideal resignado da experiência da vida humana na idade avançada do espírito, como em Dilthey, mas tampouco, como em Husserl, um ideal metódico último da filosofia frente à ingenuidade do ir-vivendo, mas ao contrário, é a forma originária de realização da pré-sença, que é ser-nomundo. Antes de toda diferenciação da compreensão nas diversas direções do interesse pragmático ou teórico, a compreensão é o modo de ser da pré-sença, na medida em que é poder-ser e "possibilidade" (GADAMER, 2011, p. 347, grifo autor).

Toda compreensão é sempre, antes, um compreender-se, haja vista que a compreensão de uma expressão não se restringe à captação imediata do que contém a expressão, mas refere-se, também, "ao descobrimento do que há para além da interioridade oculta, de maneira que se chega a conhecer esse oculto [...] Nesse sentido, vale para todos os casos que aquele que compreende projeta-se rumo a possibilidade de si mesmo" (GADAMER, 2011, p.349). A compreensão de um discurso implica, pois, sempre um projetar. Tão logo se revela um primeiro sentido do texto / do discurso, o intérprete ${ }^{8}$ tece um sentido do todo.

\footnotetext{
Naturalmente que o sentido somente se manifesta porque quem lê o texto, lê a partir de determinadas expectativas e na perspectiva de um sentido determinado. A compreensão do que está posto no texto consiste precisamente na elaboração desse projeto prévio, que, objetivamente, tem que ir sendo constantemente revisado com base no que se dá conforme se avança na penetração do sentido (GADAMER, 2011, p. 356).
}

\footnotetext{
${ }^{8}$ Intérprete, aqui, corresponde àquele que se lança no discurso, na direção de uma compreensão, visto que toda compreensão diz de uma interpretação, de uma possibilidade compreensiva de ver / olhar o fenômeno interrogado.
} 
Nessa direção, a compreensão de um discurso - seja de um texto ou de um diálogo 9 - não implica o esquecimento ou negação de todos os conhecimentos prévios sobre seu conteúdo ou, mesmo, das opiniões próprias do intérprete-interlocutor, mas exige a simples abertura para o horizonte compreensivo do outro / do texto. Tal abertura "implica sempre colocar a opinião do outro em alguma relação com o conjunto das opiniões próprias, ou que a gente se ponha em certa relação com elas" (GADAMER, 2011, p. 358). A partir de tal possibilidade, a compreensão de um discurso (texto ou diálogo) pressupõe a "tradição" como condição fundamental ao acontecer de uma produção - por-adiante -, afastando-se da perspectiva compreensiva que concebe a précompreensão como uma forma distorcida do pensamento, que precisa ser lapidado antes de acessarmos uma compreensão correta do mundo, das coisas, dos outros e de nós mesmos (LAWN, 2007).

Para Gadamer, ao assumir o caminho apontado por Heidegger, a tradição não é algo externo, da qual podemos livrar-nos, mas apenas alguma coisa que podemos interrogar, possibilitando mudar aqueles pré-conceitos históricos que dificultam nossos esforços de compreender os outros, a nós mesmos e ao mundo (SCHWANDT, 2008). Seria ingenuidade achar que podemos nos livrar de nossa tradição, ou, mesmo, olhar de forma neutra para um fenômeno, visto que a compreensão diz respeito ao próprio existir, ser-no-mundo-com-os-outros.

Importa lembrar que o compreender originário não diz respeito a um ato subjetivo ou mesmo intelectivo, mas implica um deixar-se estar na penumbra, que se dá entre a coisa compreendida-interrogada e o horizonte compreensivo pelo qual o intérpreteinterlocutor se desloca. Toda compreensão solicita uma receptividade à alteridade, ao estranho. Tal “receptividade não pressupõe nem uma 'neutralidade' com relação à coisa nem tampouco um anulamento de si mesma; implica antes uma destacada apropriação das opiniões prévias e preconceitos pessoais" (GADAMER, 2011, p. 358). Pois os préconceitos não reconhecidos podem tornar-nos surdos e cegos para os sentidos de que nos fala a tradição, afastando-nos da própria compreensão. Não estamos, de antemão, em condições de distinguir nossos pré-conceitos, de modo a perceber quais são aqueles que facilitam o desvelamento de outras/novas compreensões daqueles que podem levar a malentendidos. Tal distinção só será possível na própria compreensão e, por isso, Gadamer

\footnotetext{
${ }^{9} \mathrm{O}$ termo diálogo, para Gadamer, não corresponde à dialogia ou à dialética, mas ao sentido de conversação, sentido que será melhor desvelado mais à frente neste texto.
} 
(2011) entende que devemos perguntar como e sobre que condições a compreensão se mostra.

Orientado pela Hermenêutica Filosófica, o que verdadeiramente importa é darmonos conta de nossos pré-conceitos "a fim de que o próprio texto ${ }^{10}$ possa apresentar-se em sua alteridade, podendo assim confrontar sua verdade com as opiniões prévias pessoais" (GADAMER, 2011, p. 358). E, nessa direção, podemos compreender o discurso presente na clínica como narrativa pessoal, que pode ser "retecida" à medida que passa a ser compreendido apenas como um horizonte possível pelo qual algo pode ser visto / compreendido.

Pré-conceitos não dizem respeito apenas a seus juízos, mas ao horizonte compreensivo do intérprete-interlocutor que lhe permite, ao mesmo tempo, um aproximar-se e um afastar-se de um fenômeno interrogado, abrindo-o para a possibilidade do discurso e da compreensão, que é sempre histórica, “[...] constituem a realidade histórica de seu ser" (GADAMER, 2011, p. 368, grifo do autor). Nessa perspectiva, antes de ser a história que nos pertence, somos nós que pertencemos a ela. Antes de compreendermo-nos na reflexão do passado, compreendemo-nos no mundo - na família, na sociedade, na cultura, no Estado, no tempo epocal em que vivemos. Assim, a compreensão constitui “[...] um retroceder que penetra num acontecimento da tradição, onde se intermedeiam, constantemente, passado e presente" (GADAMER, 2011, p.385), revelando o movimento circular da compreensão. Círculo que não se dissolve quando a compreensão acontece, mas alcança sua realização mais autêntica ao revelar-se num jogo compreensivo que acontece no intercâmbio entre horizontes. Segundo Gadamer (2011, p.395),

[...] Enquanto está em jogo, é impossível fazer com que um preconceito salte aos olhos; para isso é preciso de certo modo provocá-lo. Isso que pode provocálo é precisamente o encontro com a tradição, pois o que incita a compreender deve ter-se feito valer já, de algum modo, em sua própria alteridade. Já vimos que a compreensão começa onde algo nos interpela. Esta é a condição hermenêutica suprema.

Importa, aqui, observar que esse algo que nos interpela é sempre o mundo da vida, mundo compartilhado, no qual somos e que nos constitui enquanto ser-no-mundo-juntoaos-outros-e-a-nós-mesmos. Haja vista que ser é sempre num mundo compartilhando, ser-com e, nesse sentido, singular e, ao mesmo tempo, plural (alteridade). Enquanto ser-

\footnotetext{
${ }^{10}$ Onde se escreve texto, podemos compreender o outro, a alteridade, o estranhamento.
} 
no-mundo estamos sempre compreendendo e sendo tocados por aquilo que nos vem ao encontro, inclusive, nós mesmos enquanto poder-ser, abertura de sentido.

A compreensão, que se dá nesse jogo que já sempre somos, aproxima-se da estrutura da pergunta, que consiste em abrir e manter possibilidades. O sentido de jogo aqui assumido rompe com seu significado subjetivo predominante em todas as concepções estéticas e antropológicas tradicionais que partem de uma "filosofia da subjetividade", que podem permear as pesquisas científicas e as teorias e práticas psicológicas clássicas.

Nessa perspectiva, seu sentido não pode ser reduzido a simples contraposição de uma consciência à outra ou mesmo a um objeto, mas “[...] o jogo tem uma natureza própria, independente da consciência daqueles que jogam. O jogo encontra-se também lá, sim, lá propriamente lá, onde nenhum ser-para-si da subjetividade limita o horizonte temático e onde não existem sujeitos que se comportam ludicamente" (GADAMER, 2011, p.155). O jogo, assim assumido, resguarda o estar-jogado/lançado de modo que seu movimento não se fixa em nenhum alvo, nem depende de nenhum sujeito fixo. É o próprio movimento como tal, é ele "[...] que mantém o jogador a caminho, que o enreda no jogo e que o mantém nele" (GADAMER, 2011, p.160), e, assim, transforma quem dele participa. Abriga, nesta direção, o próprio risco de não “[...] saber se 'vai', se 'conseguirá' e se 'voltará a conseguir'” (GADAMER, 2011, p.160), seu caráter lúdico reside, pois, na sua própria indeterminação e na possibilidade de desvelar outro sentido, ou mesmo, de perder-se e fracassar.

Seria, pois, ingênuo achar que, quando um pré-conceito se torna questionável, frente ao que nos diz o outro, ele é deixado de lado em prol do outro (do diferente), que viria substituir aquele imediatamente. Um pré-conceito só entra, realmente, em jogo à medida que já se está metido nele; e, só quando está em jogo, é capaz de apreender a pretensão desvelada no horizonte do outro, possibilitando que ele também entre no jogo. Ou seja, toda pergunta, enquanto abertura, só tem sentido à medida que sua delimitação já se dá através de um horizonte, numa perspectiva ou direção. A esse respeito, Gadamer (2011, p.498) ressalta que "quando se pergunta, abrem-se possibilidades de sentido, e com isso aquilo que possui sentido passa para a opinião pessoal”. Nessa direção, compreende que perguntar é experimentar possibilidades e não as pôr.

A interpretação se dá na interpenetração de horizontes, “[...] âmbito de visão que abarca e encerra tudo o que pode ser visto a partir de um determinado ponto" (GADAMER, 2011, p. 399). Tal acontecimento não corresponde à imposição de um dos 
horizontes sobre o outro, mas obedece às condições de cada um desses horizontes que se lançam no jogo compreensivo. A compreensão dá-se, pois, em uma fusão de horizontes que nunca poderá ser obtida em sua totalidade, nem completamente finalizada (LAWN, 2007; SCHWANDT, 2008), visto que um horizonte corresponde a "[...] algo no qual trilhamos nosso caminho e que conosco faz o caminho. Os horizontes se deslocam ao passo de quem se move" (GADAMER, 2011, p. 402).

Para Gadamer (2011, p. 492, grifo do autor), a fusão de horizontes, que se dá na compreensão, "[...] é o genuíno desempenho e produção da linguagem”, visto que "[...] se dá justamente nesse vir-á-fala da própria coisa em pauta” (p. 493). E não porque, em um segundo momento, ela é, também, apreendida em palavras. Importa lembrar que a linguagem não é um atributo secundário do ser-do-homem-no-mundo, mas é nela que ser e mundo se mostram / são. Nessa perspectiva, toda compreensão só acontece numa verdadeira conversação, que abrirá uma linguagem comum entre os interlocutores de um discurso. Algo é posto e isso possibilita que os interlocutores se aproximem e se afastem de modo que tais possibilidades se alterem mutuamente, na linguagem, de modo que aquilo que se era, já não se é mais, pois:

Como uma palavra puxa a outra, como a conversa toma seus rumos, encontra seu curso e seu desenlace, tudo isso pode ter algo como uma direção, mas nela não são os interlocutores que dirigem: eles são os dirigidos. O que "surgirá" de uma conversação ninguém pode saber de antemão. $\mathrm{O}$ acordo ou seu fracasso é como um acontecimento que se realiza em nós. [...] compreender o que alguém diz é pôr-se de acordo na linguagem e não transferir-se para o outro e reproduzir suas vivências (GADAMER, 2011, p. 497, sic.).

Acordo, aqui, não diz respeito a um contrato estabelecido previamente ou de antemão, mas a possibilidade de uma fusão de horizontes que se direciona para o "descobrimento" de uma interpretação que emerge em uma "conversa-ação" entre dois ou mais horizontes, que assumem a direção da pergunta / do perguntar. A conversação corresponde a um processo de pôr-se de acordo, o que implica repousar, aguardar junto ao outro de modo a dar espaço para seus pontos de vista. Convoca-nos a ponderar as opiniões, as nossas e as do outro, de modo que seja possível desvelar uma linguagem comum. Para que isso aconteça, Gadamer (2011, p. 501) pontua que se faz imprescindível que "os interlocutores estejam dispostos a isso, abrindo espaço para acolher o estranho e o adverso". Quando ambos se colocam na relação dessa forma - uma vez que a condição ontológica do poder-ser é disposição afetiva e pré-compreensão -, os interlocutores conseguem considerar e manter os argumentos e contra-argumentos, possibilitando através de uma transferência recíproca, imperceptível e não arbitrária - chegar a uma 
linguagem e a uma decisão comum. Essa linguagem “[...] coincide com a própria realização do compreender e do acordo" (GADAMER, 2011, p.502), sendo mais do que uma mera adaptação. Ela diz de ambos os horizontes, sem se reduzir a nenhum deles, revelando-se como algo novo que só é possível no acontecer desse jogo compreensivo interlocução e interpenetração.

\begin{abstract}
De certo que quem foi criado numa determinada tradição cultural e de linguagem vê o mundo de uma maneira diferente daquele que pertence a outras tradições. De certo que os "mundos" históricos, que se dissolvem uns nos outros no decurso da história, são diferentes entre si e também diferentes do mundo atual. E, no entanto, o que se representa é sempre um mundo humano, isto é, um mundo estruturado na linguagem, cada um desses mundos está aberto, a partir de si, a toda concepção (Einsicht) possível e, assim, a toda espécie de ampliação de sua própria imagem de mundo e, nesse sentido, acessível a outros. [...] a perfectibilidade infinita da experiência humana de mundo significa que, em qualquer linguagem que nos movamos, jamais alcançaremos outra coisa além de um aspecto cada vez mais amplo, uma "visão" (Ansicht) de mundo (GADAMER, 2011, p. 577).
\end{abstract}

Nessa direção, podemos compreender que qualquer trabalho ou pesquisa que assume os pressupostos da Analítica Existencial e/ou da Hermenêutica Filosófica, não tem pretensões de esgotar o fenômeno interrogado ou mesmo finalizar a interrogação que foi levantada. Mas, por meio de uma conversação, busca ampliar a visão de mundo, "descobrir" outros horizontes compreensivos pelos quais o fenômeno interrogado pode ser visto / compreendido. O que implica não esquecer que toda compreensão é sempre uma interpretação, descrição ôntica que se dá no jogo hermenêutico, de modo que tal possibilidade compreensiva, antes mesmo de dar resposta, abre-se na direção da pergunta. Nessa perspectiva, toda e qualquer compreensão que possa chegar ao não-velamento, revela-se apenas como uma possibilidade interpretativa de se olhar/ver um fenômeno a partir de um horizonte possível.

Feita essa breve apresentação de alguns pressupostos da hermenêutica existencial - ao modo de Heidegger e Gadamer -, passamos, agora, a pensar o caminho desvelado na pesquisa realizada no trabalho da tese. Pesquisa que, como já citado, objetivou problematizar a prática psicológica com famílias no contexto de "serviços-escola", na direção de propor horizontes compreensivos / interventivos mais afinados à experiência singular que marca a situação clínica.

\title{
3 Descrição do Método: o caminho tecido
}


Passamos, agora, a descrever o caminho revelado no acontecer de uma pesquisa para subsidiar um trabalho de tese que visou a problematizar a prática psicológica com famílias no contexto dos "serviços-escola". Importa destacar que o caminho, aqui, narrado mostrou-se a partir da própria aproximação com o fenômeno interrogado.

Ao não partir de um trilho já previamente determinado, muitas curvas e desvios se mostraram nesse caminhar, solicitando-nos repensar constantemente as direções que íamos assumindo. Como horizonte de partida, tínhamos apenas algumas inquietações / perguntas, tais como: Como os serviços-escola de cursos de graduação em Psicologia, no estado de Pernambuco, têm ofertado atenção às demandas familiares? Como esses serviços estão "cuidando" das famílias que vêm à procura de atendimento psicológico? Tais modos de "cuidado" correspondem aos apelos que se mostram nos pedidos de ajuda? Há, nesses modos de "cuidar", algum lugar para o mistério próprio ao existir humano?

Importa destacar que, ao partir do horizonte aberto pela hermenêutica existencial, o caminho percorrido revelou-se na aproximação e no aguardar demorado junto às inquietações que motivaram seu acontecimento, acolhendo um caminho que foi dando-se ao caminhar. Nossos esforços dirigiram-se na direção de ampliar nossas próprias compreensões acerca do fenômeno interrogado, de modo que os encontros com outros horizontes pudessem mostrar outras visões.

\subsection{Contextualização do campo e apresentação dos participantes: caminhos apontados}

Como a tese se constituiu em uma pesquisa qualitativa "orientada" por pressupostos hermenêuticos existenciais, nosso horizonte de partida convocou-nos a uma aproximação com o campo interrogado, na direção de recolher dimensões que, ali, se mostravam. Para tanto, antes de assumirmos pressupostos teorético-explicativos já manifestados acerca da temática interrogada, decidimos que o caminho inicial, a ser seguido, era lançarmo-nos ao encontro de alguns "serviços-escola" "11, vinculados ao curso

\footnotetext{
${ }^{11} \mathrm{O}$ termo "serviço-escola" surge a partir das críticas realizadas à nomenclatura "clínica-escola", como era denominado o lugar voltado para o estágio obrigatório de alunos do curso de Graduação em Psicologia Clínica. Com a expansão da prática psicológica para além dos consultórios e, consequentemente, a aderência de outros serviços e intervenções vinculados aos estágios obrigatórios, o termo "serviço-escola" passou a ser adotado em contraposição ao termo clínica-escola. Importa destacar, ainda, que o termo clínicaescola denomina, na maior parte das vezes, um espaço físico pertencente a Instituições de Ensino Superior (IES), no qual é ofertado um lugar para a prática de estágio e, ao mesmo tempo, atendimento à comunidade. Enquanto "serviço-escola" nomeia algo mais amplo, que ultrapassa as fronteiras físicas e geográficas da IES, englobando práticas de estágio que podem acontecer em diversas instituições e contextos sociais.
} 
de Graduação de Psicologia de Instituições de Ensino Superior (IES) do estado de Pernambuco.

Nessa direção, visitamos três clínicas-escola ${ }^{12}$, as quais - após autorização de seus responsáveis, da assinatura da Carta de Anuência e da aprovação do projeto de pesquisa pelo Comitê de Ética - pudemos transitar e ter acesso aos seus prontuários, registros de atendimentos psicológicos realizados por estagiários. Importa ressaltar que duas dessas clínicas pertenciam a instituições privadas de ensino superior localizadas na capital pernambucana, enquanto a terceira era de uma instituição pública federal do sertão pernambucano. E todas estavam vinculadas a cursos de Psicologia reconhecidos, legitimados e bem-conceituados nesse Estado.

Nessas três instituições, tivemos acesso, ao todo, a 300 prontuários, que se encontravam no arquivo morto e registravam atendimentos psicológicos realizados por estagiários entre os anos de 2004 a 2010. Desses, 89 foram selecionados para serem analisados $^{13}$, uma vez que apontavam, de algum modo, para uma demanda familiar, seja de modo explícito ou implícito. O primeiro contato com esses prontuários foi realizado em um caderno de anotações, com o registro de algumas informações, tais como: queixas e demandas; quem procurou pelo atendimento; quem foi atendido; como se sucederam os atendimentos; quantos atendimentos foram realizados; a que modalidade de prática psicológica se recorreu; e quais foram os encaminhamentos e/ou desfechos apresentados nessas situações clínicas.

Ainda, com intuito de nos aproximarmos da temática interrogada, o caminho assumido apontou para a possibilidade de tecer diálogos com alunos e profissionais de psicologia (supervisores e técnicos) que tivessem uma ação vinculada a "serviços-escola" que atendessem famílias. Para tanto, entramos em contato com quatro professoras/supervisoras, uma de uma IES da capital pernambucana, duas do sertão e uma do agreste pernambucano. Dessas, três pertenciam a instituições públicas de ensino e todas, por coincidência, eram mulheres.

Práticas que podem ser vinculadas aos estágios introdutório (básico) e/ou específico ou, mesmo, a projetos de extensão.

${ }^{12} \mathrm{O}$ termo clínica-escola, aqui, é adotado porque não apenas entramos em contato com o "serviço-escola" das três instituições visitadas, mas transitamos pelo espaço físico das clínicas vinculadas ao curso de Psicologia dessas instituições.

13 A compreensão de análise aqui assumida remete à compreensão apontada por Heidegger (2009), ao destacar que o termo análise apareceu pela primeira vez no livro Odisseia de Homero para designar o movimento de Penélope ao tecer o manto mortífero de Ulisses, nomeando o movimento dela de tecê-lo durante o dia e de destecer durante a noite. Nesse sentido, analisar remete ao "des-tecer", soltar de nós. 
A pesquisa contou, ainda, com a participação de uma técnica de psicologia de uma instituição de ensino federal, situada no sertão pernambucano, além da colaboração de dezesseis alunos de Psicologia, 5 vinculados a uma IES estatual e 11 a uma instituição particular.

Importa ressaltar que, como o intuito da tese era problematizar / compreender como a prática psicológica com famílias vem mostrando-se no contexto dos "serviçosescola" em Pernambuco, esses alunos e profissionais que participaram da pesquisa não estavam necessariamente vinculados a uma das três clínicas-escola visitadas. Pois compreendíamos que, quanto mais amplo fosse esse campo, mais horizontes compreensivos poderiam mostrar-se e, nesse sentido, mais "ricas" seriam as compreensões que daí se revelavam.

Faz-se necessário deixar claro que esses participantes foram convidados / selecionados a partir da relevância que tinham para a temática pesquisada. De modo que, a população da pesquisa constituiu-se de uma "amostra intencional". Essa se caracteriza pela escolha de um grupo pequeno de pessoas e / ou instituições convidadas a participar de uma pesquisa devido à relevância que tem para a temática pesquisada (THIOLLENT, 1986; TURATO, 2003).

\subsection{Caminho assumido: recursos recorridos}

Enquanto recursos, no caminhar da tese, mostraram-se como possíveis "vias" para a tessitura de uma aproximação com facetas do fenômeno interrogado: a análise documental; a entrevista narrativa; as "rodas de conversa"; e os "diários de bordo" da pesquisadora-doutoranda.

Acerca da análise documental, importa destacar que ela se dá pela análise de documentos que não receberam ainda nenhum tratamento científico, exigindo um olhar crítico do pesquisador diante do material que pretende analisar, possibilitando lê-lo nas suas entre linhas (SÁ-SILVA; ALMEIDA; GUINDANI, 2009). Entende-se por documento qualquer registro escrito, oral e/ou visual que objetiva registrar um fenômeno, possibilitando interrogá-lo após o seu acontecimento. "Recurso" que nos permitiu, num primeiro momento, realizar uma aproximação com os prontuários selecionados, fazendo, como já enunciado, alguns registros em um caderno de anotação. Registros que foram, posteriormente, no momento de tessitura da análise da tese, recorridos e revisitados, várias vezes, com o intuito de recolher as dimensões / horizontes que neles se mostravam. 
No que diz respeito a entrevistas narrativas, Flick (2009) destaca que elas surgiram diante do ceticismo de alguns pesquisadores acerca de como e até que ponto as experiências particulares podem ser acessadas por via de um esquema estruturado de perguntas e respostas, surgindo como alternativa às entrevistas estruturadas ou semiestruturadas. Na busca de caracterizar este "instrumento", o autor lembra que a entrevista narrativa parte de uma pergunta "gerativa", que tem por destino estimular a contação (narrativa) da experiência do entrevistado e que toda e qualquer intervenção que possa ser feita deve acompanhar o fluxo da própria narrativa, de modo a apenas clarear dimensões que ainda tenham ficado obscuras à compreensão do pesquisador.

As entrevistas narrativas foram realizadas, individualmente, com as professoras/supervisoras e com a técnica de psicologia. Elas aconteceram no lugar e em um horário de maior conveniência para cada uma das colaboradoras, de modo que não houvesse nenhum prejuízo financeiro às participantes, conforme determina as normativas dos Comitês de Pesquisa com seres humanos.

As entrevistas foram gravadas, posteriormente, transcritas e devolvidas para que as participantes pudessem veracizá-las. Tal devolução é realizada à medida que compreendemos que a leitura da narrativa, que se dá no encontro entre o participantenarrador e o pesquisador, mostra-se como outra possibilidade de apropriação do vivido, permitindo àquele que narra sua história (ao participante) retecer suas impressões / compreensões acerca de sua experiência-narrada. Constitui-se outra possibilidade de desvelamento de sentido.

Sobre as rodas de conversas, vale observar que, num primeiro momento, elas se aproximam do que Flick (2009, p.181) chama de entrevistas de grupo, compreendidas por ele como uma "forma de ampliar a situação da entrevista", na qual o pesquisador assume o papel de um mediador. Nesse sentido, o pesquisador destina-se a aguardar o movimento da fala, de modo que nenhum participante "ou grupos parciais dominem com suas contribuições, a entrevista e, consequentemente, todo o grupo" (FLICK, 2009, p.181). Elas, também, iniciam-se com uma questão inquietadora.

Importa atentar que, mesmo diante de modos singulares de ver / compreender um fenômeno, a situação grupal pode favorecer a construção de uma linguagem comum a partir do compartilhamento de experiências pelos colaboradores frente a um fenômeno sobre o qual um pesquisador se lança a interrogar / compreender. Nessa perspectiva, à medida que o pesquisador acompanha o próprio desenrolar do grupo, a situação pode abrir-se para o acontecer de uma "fusão de horizontes", revelando-se como uma conversa- 
em-ação, fusão de horizontes. Nesse sentido, afasta-se da proposta de Flick (2009) por não poder ser pensada simplesmente como procedimentos técnicos previamente definidos, aproximando-se do que Gadamer (2011) nomeia de "conversação".

Enquanto recurso recorrido, as rodas de conversa mostraram-se como possibilidade de tecer um diálogo com os alunos, que assim como as entrevistas narrativas partiram de uma questão disparadora: Como vocês compreendem, a partir da prática de vocês, o atendimento a famílias nesse contexto do "serviço-escola"?. Tal caminho de aproximação com os alunos num primeiro momento foi apontado pelo próprio campo de pesquisa ao solicitarmos a uma professora-supervisora uma conversa com alguns de seus estagiários. Diante de tal solicitação, ela propôs que essa conversa fosse realizada em grupo, o que se mostrou bastante frutífero para esse caminhar, pois, apresentou-se como possibilidade de um grupo de alunos - que partilham um mesmo espaço de supervisão, seja no estágio obrigatório ou num projeto de extensão - compartilhassem suas impressões e sentimentos, constituindo-se num momento de "co-produção" de sentido.

Diante desse horizonte, acabamos realizando três rodas de conversa: uma que contou com a presença de 6 alunos; uma segunda, com 5 outros alunos; e uma terceira com mais 5 alunos de uma instituição estadual do agreste pernambucano. Essas conversas foram gravadas ou registradas manualmente, quando a gravação não foi autorizada (como aconteceu com as duas primeiras rodas realizadas com alunos de uma instituição particular da capital pernambucana). A partir da gravação ou dos apontamentos anotados em cada uma das rodas, foram construídos textos-compreensivos (um para cada roda). Eles mostraram-se como uma "primeira" possibilidade compreensiva revelada no entrelaçamento dos diversos horizontes que se apresentaram no diálogo tecido entres os participantes de cada roda, incluindo o do pesquisador. Esses textos foram devolvidos para os participantes de cada roda, de modo que eles poderiam acrescentar, modificar ou propor alguma alteração no texto. Esses textos foram, posteriormente, resgatados para a tessitura da análise apresentado na tese.

Tanto a entrevista narrativa como a roda de conversa revelaram-se enquanto recursos que possibilitaram o recolhimento de múltiplas narrativas. Vale clarear que o sentido de narrativa, aqui assumido, comunga com o pensamento de Walter Benjamim. Segundo esse autor (1994), o narrador corresponde àquele que tem como fonte de inspiração sua experiência e seu discurso diz de si e do seu vivido, ao mesmo tempo em que se abre ao ouvinte / leitor, incluindo-o no campo interpretativo de sua experiência, à medida que se dispõe ao diálogo. A "arte de narrar" pode impor aos interlocutores o 
descobrimento de uma linguagem compartilhada que, ao se lançarem no jogo, possibilita a ampliação de seus campos de visões. Há, assim, a possibilidade de alargar o campo compreensivo acerca do fenômeno interrogado / narrado, sem, todavia, esgotar suas possibilidades interpretativas à medida que outras interpretações / compreensões possíveis chegam ao não-velamento. A esse respeito, Benjamim (1994, p. 25) destaca que a "arte de narrar" é,

[...] num certo sentido, uma forma artesanal de comunicação. Ela não está interessada em transmitir o "puro em si" da coisa narrada como uma informação ou um relatório. Ela mergulha a coisa na vida do narrador para em seguida retirá-lo dele. Assim se imprime na narrativa a marca do narrador como a mão do oleiro na argila do vaso.

Tal acontecimento aproxima-se de uma conversação, assim como pensada por Gadamer (2011), fenômeno que possibilita que uma compreensão se revele. Visão que não corresponde a uma adequação da coisa ao real, como pretendem as ciências exatas, mas uma nova direção, modo de olhar que diz tanto dos interlocutores como do fenômeno interrogado / narrado. Nessa direção, Schimidt (1990, p.72) destaca que a narrativa “supõe uma 'conversação continuada' entre narrador e pesquisador, sobre uma temática escolhida pelo pesquisador, em função dos interesses de seu trabalho". Tal relato, assim compreendido, abre-se para a possibilidade de elaboração e transmissão da experiência, que permite incorporar múltiplas orientações acerca dos horizontes compreensivos, das visões de mundo, sem alcançar sua totalização.

Já no que diz respeito ao "diário de bordo", esse mostrou-se como um recurso de pesquisa que contempla narrativas / testemunhos escritos de próprio punho pelo pesquisador, disposto a compartilhar suas impressões, observações e sentimentos vivenciados em uma experiência e / ou observação. Nessa direção, Aun e Morato (2009, p.123) ressaltam que o diário "[...] é como o tecer de muitas histórias interligadas. [...] transpassa um simples relatório descrito: diz da experiência de cada um, sem que nela tudo" seja regido pelos mesmos princípios. Nessa direção, os diários constituem testemunhos escritos de experiências vivas, para além de uma simples descrição, são o narrar de uma história a próprio punho.

Tal narrativa-escrita revela-se, pois, como possibilidade de apropriação de uma experiência à medida que pode constituir-se numa tentativa de elaboração do acontecido, aproximando-se das compreensões, sentimentos e observações desvelados na situação vivida. É, pois, a possibilidade de uma construção, desconstrução e reconstrução de sentido, de um fazer em ação que permite caminhar entre veredas nunca antes 
desbravadas. Como ressalta Prado (2013), é um lançar-se diante do desconhecido, aventurando-se, correndo riscos e espantando-se diante do mistério advindos das novas "des-cobertas", ao mesmo tempo em que se dispõe para compartilhar as impressões e sentimentos aí revelados.

Os diários de bordo da pesquisadora-doutoranda foram realizados a partir do compartilhamento, a próprio punho, de suas experiências - sentimentos e compreensões acerca dessas - tanto na prática clínica junto às famílias, como durante o caminhar de seu trabalho de tese na aproximação com os prontuários e com os participantes da pesquisa.

\subsection{A tessitura das compreensões "des-veladas" no caminho assumida}

Importa deixar claro que as compreensões que foram tecidas, ao longo do trabalho de tese, mostraram-se apenas como um horizonte possível de olhar / ver o fenômeno interrogado. Âmbito de visão que se desvelou a partir de uma "fusão de horizontes". Ou seja, a partir do entrelaçamento dos múltiplos horizontes que constituíram a pesquisa - o horizonte da pesquisadora, dos participantes, dos prontuários, dos “diários de bordo", dos pressupostos assumidos e dos autores recorridos -, que abriram a possibilidade de uma co-construção de sentido, possibilitando, assim, reflexões acerca da prática psicológica com famílias no contexto dos "serviços-escola" a partir de um diálogo (conversação / “conversa-em-ação").

Nessa direção, foi possível observar que os horizontes abertos pela base fenomenal da tese apontaram para a insuficiência das premissas teorético-explicativas das teorias psicológicas clássicas - que assumem a concepção de sujeito intrapsíquica e de clínica prescritiva - para o recolhimento da singularidade que se revela na situação clínica, principalmente, com famílias. Convocando-nos a destinarmos por caminhos outros que privilegiem a existência humana em seu acontecer, resguardando, assim, a dimensão de mistério que a constitui.

A situação clínica com família apresentou-se como "espaço" no qual múltiplos discursos singulares e, ao mesmo tempo, plurais podem revelar-se. Nesse sentido, convoca ao psicólogo a "cuidar-de-ser-si-mesmo-junto-a-seus-pacientes ${ }^{14}$ ” de modo que

\footnotetext{
${ }^{14}$ A concepção de paciente não se aproxima, aqui, à comumente assumida enquanto ser que é passivo e que se encontra submetido, exclusivamente, ao domínio do outro. Mas no seu sentido mais originário, visto que paciente vem de pathos, seria aquele que sofre e, nesse sentido, encontra-se enredado em seu sofrer, em sua história.
} 
tal situação não se transforme em atendimentos individuais em grupo, mas lance-se na direção de possibilitar que todos os discursos se façam presentes, à medida que solicita a cada membro familiar fazer valer, em si, o estranho e o diverso. Tal direção abre-se para a possibilidade de que cada membro da família aproxime do modo como estão cuidando de ser-em-na-família, do modo como está-sendo-uns-com-os-outros. Solicitando-lhes, assim, a refletir como tem caminhado singularmente em tal contexto. "Tarefa" que se revelou ser nada fácil e, até mesmo, não garantida.

Nessa direção, a pesquisa possibilitou compreender que esse fazer parece nos desafiar e que podemos respondê-lo de inúmeros modos, sendo imprescindível reconhecer pelo menos dois: o modo do "des-abrigo" presente na técnica moderna, que visa à exploração e à dominação; e outro que se dá por uma atitude que aguarda serenamente o revelar daquilo que se acompanha em seu movimento de revelação ocultação. Esse segundo modo de ser-com parece guardar "espaço" para o mistério constitutivo do próprio poder-ser.

Importa lembrar que dispor-se nesse modo de ser-com não depende apenas de uma ato de vontade - visto que já nos encontramos-sempre-no- mundo-com-os-outros-e-comnos-mesmo a partir de uma pré-compreensão (um âmbito de visão, a nossa tradição) e de uma disposição afetiva -, todavia, ele apareceu enquanto possibilidade de direcionarmonos para a possibilidade de poder dizer sim e não aos apelos desse mundo técnico que habitamos.

Nessa direção, tornou-se claro que uma prática psicológica clínica com família não pode ser traçada por caminhos já "dis-postos" e previamente prescritos antes mesmo do próprio acontecer de tal situação, principalmente, à medida que se destina ao recolhimento do fenômeno que se revela em sua singularidade. Assim, a prática psicológica não pode ser pensada enquanto um protocolo técnico que pode ser reaplicado em situações diversas de atendimento a famílias. E nem haverá um caminho já previamente determinado. Mas assumir os horizontes abertos pela hermenêutica existenciais, convoca ao psicólogo a lançar-se diante do desconhecido, atentando-se e zelando para que o encontro que se dá nessa situação clínica convoque os membros de uma família a se apropriarem dos modos como estão-cuidando-de-ser-uns-com-os-outros.

Nessa direção, a pesquisa apontou para a importância de reconhecermos que a demanda familiar ultrapassa qualquer compreensão de subjetividade, visto que se remete aos acontecimentos partilhados em uma família e por uma família, sem esquecer que o modo como cada um se encaminha nessa pluralidade é sempre singular. Frente a tal 
horizonte, a pesquisa revelou a insuficiência de se pensar a prática psicológica com famílias a partir da lógica prescritiva do diagnosticar para tratar, centrada em uma concepção de sujeito e normalidade. A partir do horizonte aberto pela pesquisa, a prática psicológica não pode ser normatizada, mas tão somente descrita a partir do acolhimento dos indicadores formais ${ }^{15}$ que se revelam em seu acontecer. $O$ que aponta para a necessidade de se orientar pelos caminhos desvelados em um questionar constante, visto que o dizer não se esgota em um saber, à medida que cada saber é um horizonte pelo qual um fenômeno poder ser visto / questionado / compreendido.

Por fim, no que diz respeito à base fenomenal da pesquisa de tese que deu origem a esse artigo, importa deixar claro que as compreensões nela tecidas - e, aqui, resumidamente apresentadas - não esgotam as possibilidades compreensivas acerca do fenômeno interrogado: a prática psicológica com famílias no contexto dos "serviçosescola". Tais compreensões não devem ser vistas como premissas que devem ser seguidas, mas apenas são horizontes possíveis pelos quais a prática psicológica com famílias pode ser refletida. Horizonte que parece convocar a assumir caminhos que rompem com o fazer puramente prescritivo, na direção do desbravamento de outros caminhos que resguardem a dimensão de indeterminação e imprevisibilidade que constituem o próprio poder-ser-no-mundo-com-os-outros, condição originária desse ente que nós mesmos somos, enquanto existentes.

\section{Considerações finais: algumas ressonâncias dos pressupostos hermenêuticos existenciais para a pesquisa em Psicologia Clínica}

Por fim, importa reconhecer que pensar a pesquisa a partir dos horizontes apontados pela ressonância dos pressupostos hermenêuticos existenciais implica afastarse de uma concepção que compreende caminho-método enquanto simples aplicação de procedimentos técnico-metodológicos previamente determinados, assumindo uma concepção que nos aproxime da compreensão ontológica acerca da existência. Tal horizonte convoca o pesquisador a lançar-se por caminhos não previamente definidos / trilhados, mas que se revelam no próprio "partejar" daquilo que se mostra na direção da pergunta. Impõe ao pesquisador atentar-se para os inesperados que se dão nesse encaminhar, solicitando flexibilidade e criatividade para interrogar e rever caminhos, na

\footnotetext{
${ }^{15}$ Aquilo que se mostra, indica, mas não determina ou impõe conclusões, apenas orienta / aponta.
} 
busca de recolher facetas que se mostram em tal situação, atentando-se para o horizonte que se revela numa "fusão de horizontes".

Tal perspectiva impõe reconhecer a impossibilidade da tessitura de generalizações à medida que revelam que cada situação é radicalmente única. Compreender a experiência que acontece singularmente na existência humana solicita o desvelamento de outros modos de aproximação, para além dos modelos técnico-quantificadores.

Faz-se imprescindível, ainda, reconhecer que a compreensão que se desvela em um caminhar, constitui-se apenas em um horizonte compreensivo possível, e nada além disso. Nenhum horizonte jamais esgotará todas as possibilidades compreensivas acerca de um mesmo fenômeno, isso se dá não devido a uma falha ou limitação cognitiva, mas devido ao próprio movimento que constitui o jogo compreensivo, ou seja, qualquer possibilidade compreensiva.

Diante de tal perspectiva, uma pesquisa no campo da Psicologia Clínica que parte de pressupostos hermenêuticos existenciais não pode pretender-se a generalizações ou universalizações de seus "achados", mas tão somente visar ao desocultamento de novos horizontes, atentando-se para o ainda-não-dito. Não porque ele não foi ainda verbalizado, mas porque o próprio mistério constitui o existir humano e, nesse sentido, a existência (e "seus acontecimentos") não pode ser predita ou mesmo explicada racionalmente, mas apenas vivida e, talvez, refletida e compreendida. O que convoca o pesquisador a um modo de ser que aguarda "silenciosamente" e "pacientemente" que as coisas se mostrem a partir do seu próprio ocultamento. Parece, pois, que tal pesquisador deve encaminharse com prudência e delicadeza de modo a preocupar-se para que dimensões ontológicas não sejam ontificadas e, ao mesmo tempo, para que questões ônticas do existir não sejam ontologizadas. Tal aproximação convoca o pesquisador a guardar o "espaço" no qual tais dimensões se tocam sem, todavia, misturarem-se, não ontologizando o que é da clínica (ou da dimensão da pesquisa), nem "clinicalizando" o que é da ontologia.

Por fim, faz-se importante observar que, ao reconhecer tais limitações e distinções, tal encontro possibilita pensar outro caminho para a pesquisa em Psicologia Clínica e para a prática psicológica, inclusive, com famílias. Caminhos que desvelam um modo de sercom que se abre para o recolhimento da singularidade-plural que constitui cada um de nós em nosso acontecer existencial fáctico e factível. E, nesse sentido, possibilita pensar a clínica enquanto um espaço que visa a refletir esse ser biográfico, que somos em nosso próprio acontecer, resguardando as dimensões do inesperado e do imprevisível que constituem o próprio existir humano. Dimensões que não podem ser vislumbradas, na 
maior parte das vezes, pelas premissas teorético-explicativas das teorias psicológicas clássicas vigentes, à medida que essas visam à universalização do singular; e nem pesquisadas a partir da simples aplicação de procedimentos técnicos-explicativos quantificadores.

\section{Referências}

AUN, H. A.; MORATO, H. T. P. Atenção Psicológica em Instituição: Plantão Psicológico como cartografia clínica. In: MORATO, H. T. P; BARRETO, C. L. B. T.; NUNES, A. P. (Coords.). Aconselhamento Psicológico numa perspectiva Fenomenológica Existencial. 1. ed. Rio de Janeiro: Guanabara Koogan, 2009. p. 121-138.

BENJAMIN, W. O Narrador: considerações sobre a obra de Nikolai Leskov. In: BENJAMIN, W. Magia e Técnica, arte e política: ensaios sobre literatura e história da cultura. $7^{\mathrm{a}}$ ed. São Paulo: Brasiliense, 1994. p. 195-221.

CASANOVA, M. A. Nada a caminho: impessoalidade, niilismo e técnica na obra de Martin Heidegger. 1. ed. Rio de Janeiro: Forense Universitária, 2006.

CASANOVA, M. A. Apresentação à edição brasileira. In: GADAMER, H. G. Hermenêutica da obra de arte.1. ed. São Paulo: WMF Martins Fontes, 2010. p. VII-XVII.

DILTHEY, W. Ideias sobre uma psicologia descritiva e analítica. 1. ed. Rio de Janeiro: Via Verita, 2011.

FERRATER MORA, J. Dicionário de Filosofia: tomo III (K-P). 2. ed. Ipiranga: Ed. Loyola, 2004.

FERRATER MORA, J. Dicionário de Filosofia: tomo II (E-J). 2. ed. Ipiranga: Ed. Loyola, 2005.

FLICK, U. Introdução a Pesquisa Qualitativa. 3. ed. Porto Alegre: Artmed, 2009.

GADAMER, H. G. Verdade e Método I: traços fundamentais de uma hermenêutica filosófica. 11. ed. Petrópolis: Vozes; Bragança Paulista: Editora Universitária São Francisco, 2011.

GIACOIA JUNIOR, O. Heidegger Urgente: uma introdução a um novo pensar. 1. ed. São Paulo: Três Estrelas, 2013.

HEIDEGGER, M. Ser e Tempo. 2. ed. Petrópolis: Vozes, 2008.

HEIDEGGER, M. Seminário de Zollikon. 3. ed., Petrópolis: Vozes, 2009.

HEIDEGGER, M. A caminho da Linguagem. 5. ed. Petrópolis: Vozes; Bragança Paulista: Editora Universitária São Francisco, 2011.

LAWN, C. Compreender Gadamer. 1. ed. Petrópolis: Vozes, 2007.

MICHELAZZO, J. C. Do um como princípio ao dois como unidade: Heidegger e a reconstrução ontológica do real. 1. ed. São Paulo: FAPESP; Annablume, 1999. 
PRADO, R. A. A. A linguagem poética na clínica fenomenológica existencial. 2013. 211f. Tese (Doutorado em Psicologia Clínica) - Universidade Católica de Pernambuco, Recife, 2013.

SANTOS, D. G.; SÁ, R. N. A existência como "cuidado": elaborações fenomenológicas sobre a psicoterapia na contemporaneidade. Rev. abordagem gestalt., Goiânia, v. 19, n. 1, p.53-59, jul. 2013. Disponível em: <http://pepsic.bvsalud.org/scielo. php?script=sci_arttext\&pid=S1809$68672013000100007 \& \operatorname{lng}=$ pt\&nrm=iso>. Acesso em: 22 jan. 2018.

SÁ, R. N.; MATTAR, C. M.; RODRIGUES, J. T. Solidão e relações afetivas na era da técnica. Rev. Dep. Psicol., UFF, Niterói, v.18, n.2, p.111-124, dez. 2006. Disponível em: $<$ http://www.scielo.br/scielo.php?script=sci_arttext\&pid=S010480232006000200009\&lng=en\&nrm=iso>. Acesso em: 22 jan. 2018.

SÁ-SILVA, J. R.; ALMEIDA, C. D.; GUINDANI, J. F. Pesquisa documental: pistas teóricas e metodológicas. Revista Brasileira de História e Ciências Sociais, São Leopoldo, v. 1, n. 1, p. 1-15, jul. 2009.

SCHIMIDT, M, L. S. A experiência de psicólogos na comunicação de massa. 1990. $200 f$. Tese não publicada (Doutorado em Psicologia Escolar e do Desenvolvimento Humano) Instituto de Psicologia, Universidade de São Paulo, São Paulo, 1990.

SCHWANDT, T. A. Três posturas epistemológicas para a investigação qualitativa. In: DENZIN, N. K.; LINCOLN, Y. S. O planejamento da Pesquisa Qualitativa: teorias e abordagens. 3. ed. Porta Alegre: Artmed, 2008. p. 193-217.

THIOLLENT, M. Metodologia da pesquisa-ação. 3. ed. São Paulo: Cortez, 1986.

TURATO, E. R. Tratado da metodologia da pesquisa clínica-qualitativa. 2. ed. Petrópolis: Vozes, 2003.

Recebido em: 30 de janeiro de 2018.

Aceito em: 02 de julho 2018. 